\title{
Free vibration analysis of 2D-FGM truncated conical shell resting on Winkler-Pasternak foundations based on FSDT
}

\author{
A. Asanjarani ${ }^{1}$, S. Satouri ${ }^{2}, \underline{\text { A. Alizadeh }}{ }^{2}$ and M. H. Kargarnovin*
}

\footnotetext{
${ }^{1}$ Young Researchers and Elite Club, Arak Branch, Islamic Azad University, Arak, Iran

${ }^{2}$ Department of Mechanical Engineering, Arak Branch, Islamic Azad University, Arak, Iran

*Deceased
}

\begin{abstract}
Based on the first-order shear deformation theory, this paper focuses on the free vibration behavior of two-dimensional functionally graded material truncated conical shells resting on Winkler-Pasternak foundations. The materials are assumed to be isotropic and inhomogeneous in the length and thickness directions of truncated conical shell. The material properties of the truncated conical shell are varied in these directions according to power law functions. The derived governing equations are solved using differential quadrature method. Convergence of this method is checked and the fast rate of convergence is observed. The primary results of this study are obtained for (SS SL), (CS CL), and (CS SL) boundary conditions and compared with those available in the literatures. Furthermore, effects of geometrical parameters, material power indexes, mechanical boundary conditions, Winkler and Pasternak foundation moduli on the nondimensional frequency parameters of the two-dimensional functionally graded material truncated conical shell are studied.
\end{abstract}

Keywords: Truncated conical shell, free vibration, functionally graded material, differential quadrature method, Winkler-Pasternak foundations 